\title{
Evaluation of the quality of life and the impact of pain in patients with temporomandibular disorder
}

Avaliação da qualidade de vida e o impacto da dor em pacientes com disfunção temporomandibular Evaluación de la calidad de vida e impacto del dolor en pacientes con trastornos temporomandibulares

Claudio Marcio Rodrigues SANTANA JUNIOR ${ }^{1}$ Victor Augusto Alves BENTO2 Edilson José ZAFALON ${ }^{1}$ Maria Cristina MESQUITA ${ }^{3}$ Daisilene Baena CASTILLO ${ }^{1}$

${ }^{1}$ School of Dentistry of the Federal University of Mato Grosso do Sul - FAODO, 79070-900 Campo Grande - MS, Brasil ${ }^{2}$ São Paulo State University (Unesp), School of Dentistry, Araçatuba 16015-050 Araçatuba - SP, Brasil

${ }^{3}$ Tufts University School of Medicine, Boston, Massachusets, United States of America

\section{Abstract}

Objective: To evaluate the quality of life and the impact of pain in patients with Temporomandibular Disorder (TMD) Muscle/joint TMJ of a public institution in Brazil. Methods: The study consisted of two stages: the first step was the application of the Ohip-14 questionnaires, Fonseca's Anamnestic Questionnaire and the McGill Questinionaire (Br-MPQ). In the next step, after the clinical treatment, only the Ohip-14 questionnaire was applied to compare the results after the treatment. The significance level was set at $\alpha=0,05$. Results: Overall, 100 individuals were examined and diagnosis with TMD Muscle/joint TMJ. The score OHIP-14 scale before the treatment was $30.02 \pm 1.26$ (mean \pm standard error of the mean) points, being that after treatment it was $8.94 \pm$ 0.63 points, statistically significant $(\mathrm{p}<0,001)$. The mean score in the Fonseca scale was $73.25 \pm 1.93$ points. Regarding the $\mathrm{Br}$ $M P Q$, the results showed that TMD pain affects the patient in the area of work, leisure, home activities, family relationships, relationships with friends, sleep and appetite. Conclusion: SERDOF-DTM patients had severe TMD with a negative impact on quality of life, directly affecting their daily activities. The treatment proved to be effective in improving this condition.

Descriptors: Temporomandibular Joint Dysfunction Syndrome; Quality of Life; Facial Pain; Impact Profile of the Disease.

Resumo

Objetivo: Avaliar a qualidade de vida e o impacto da dor em pacientes com Desordem Temporomandibular (DTM) Músculo / ATM articular de uma instituição pública no Brasil. Métodos: O estudo consistiu em duas etapas: a primeira etapa foi a aplicação dos questionários Ohip-14, Questionário Anamnéstico de Fonseca e Questinião McGill (Br-MPQ). Na etapa seguinte, após o tratamento clínico, apenas o questionário Ohip-14 foi aplicado para comparar os resultados após o tratamento. O nível de significância adotado foi $\alpha=0,05$. Resultados: Ao todo, 100 indivíduos foram examinados e diagnosticados com DTM muscular / articular. O escore da escala OHIP-14 antes do tratamento foi de 30,02 $\pm 1,26$ (média \pm erro padrão da média) pontos, sendo que após o tratamento foi de $8,94 \pm 0,63$ pontos, estatisticamente significante $(p<0,001)$. 0 escore médio da escala de Fonseca foi 73,25 $\pm 1,93$ pontos. Em relação ao Br-MPQ, os resultados mostraram que a dor da DTM afeta o paciente nas áreas de trabalho, lazer, atividades domésticas, relações familiares, relacionamento com amigos, sono e apetite. Conclusão: Pacientes com SERDOF-DTM apresentaram DTM grave com impacto negativo na qualidade de vida, afetando diretamente suas atividades diárias. O tratamento mostrou-se eficaz na melhora desse quadro.

Descritores: Síndrome da Disfunção da Articulação Temporomandibular; Qualidade de Vida; Dor Facial; Perfil de Impacto da Doença.

\section{Resumen}

Objetivo: Evaluar la calidad de vida y el impacto del dolor en pacientes con Trastorno Temporomandibular (TTM) / TMJ en una institución pública en Brasil. Métodos: El estudio constó dos etapas: la primera etapa fue la aplicación de los cuestionarios Ohip-14, Cuestionario Anamnésico de Fonseca y Cuestionario McGill (Br-MPQ). En el siguiente paso, después del tratamiento clínico, solo se aplicó el cuestionario Ohip-14 para comparar los resultados después del tratamiento. El nivel de significancia adoptado fue $\alpha=0.05$. Resultados: En total, 100 personas fueron examinadas y diagnosticadas con TMD muscular / articular. La puntuación OHIP-14 antes del tratamiento fue de 30,02 \pm 1,26 (media \pm error estándar de la media) puntos, y después del tratamiento fue de 8,94 $\pm 0,63$ puntos, estadísticamente significativa $(p<0,001)$. La puntuación media de la escala de Fonseca fue de 73,25 \pm 1,93 puntos. En cuanto al Br-MPQ, los resultados mostraron que el dolor de los TTM afecta al paciente en las áreas de trabajo, ocio, actividades domésticas, relaciones familiares, relaciones con amigos, sueño y apetito. Conclusión: Los pacientes con SERDOF-DTM presentaron TTM grave con impacto negativo en la calidad de vida, afectando directamente sus actividades diarias. El tratamiento demostró ser eficaz para mejorar esta condición.

Descriptores: Síndrome de Disfunción de la Articulación Temporomandibular; Calidad de Vida; Dolor Facial; Perfil de Impacto de la Enfermedad.

\section{INTRODUCTION}

Facial and dental pain is the most cited aspect among the oral health indicators that impact the quality of life (QOL), followed by the loss of sleep and chewing problems ${ }^{1}$. It is accepted by the American Academy of Orofacial Pain (AAOP) that Temporomandibular Disorder (TMD) is a collective term involving a number of signs and symptoms that include joint noises such as crackling and crackling; pain in the chewing muscles; limitation of mandibular movements; facial pains; headaches and temporomandibular joint (TMJ) pain ${ }^{2,3}$.

TMDs can be classified into two major subgroups: those of articular origin, ie, those in which signs and symptoms are related to TMJ; and those of muscular origin in which the signs and symptoms are related to the stomatognathic musculature, the latter being more prevalent ${ }^{4}$. In the area of epidemiological research there are several indexes, scales and questionnaires that can be used for TMD diagnosis and evaluation. Among them, anamnetic indexes seem to be the most appropriate diagnostic tools to be administered in studies involving the general population and which may provide important information to the studied samples ${ }^{5}$. 
The self-administered questionnaire developed by Fonseca ${ }^{6}$, when compared with the diagnostic criteria for research on temporomandibular disorders (RDC), shows the advantage of shorter application time, better patient understanding and, therefore, a lower cost $^{6}$. In addition, this anamnetic index requires less need for professional diagnosis, possibility of use in public services, application in epidemiological surveys and control of treatment of diseases such as $\mathrm{TMD}^{6}$.

$\begin{array}{cc}\text { According to Barros et. }{ }^{7} \text { and John et al. }{ }^{8} \text {, } \\ \text { using } & \text { subjectial.ve health indicators, }\end{array}$ demonstrated that TMD has a great impact on the quality of life of patients with the disease. Therefore, as an evaluative factor of patients' quality of life, one of the most used instruments to measure is the Oral Health Impact Profile $(\mathrm{OHIP})^{7,9}$. This instrument measures people's perception of the social impact of oral disorders on their well-being ${ }^{8}$.

Finally, seeking to better understand the patient's perception of pain and to quantify its intensity in TMD patients, we have the Brazilian version of the McGill Pain Questionnaire (Br-MPQ), which besides measuring the different qualities of pain, provides quantitative measures and assesses the impact of pain on the patient's life with issues related to social impairment, development of daily activities and the patient's own perception of the reaction of others to their painful condition? ${ }^{9}$.

Therefore, this study aimed to knowing the psychological patients aspects of the Orofacial Pain and Temporomandibular Dysfunction Service (SERDOF-DTM) of the Faculty of Dentistry of the Federal University of Mato Grosso do Sul (FAODO-UFMS) and the resolution of the treatment offered.

\section{MATERIAL AND METHOD}

In order to perform this research, 100 patients both sexes and mean age of \pm 45.6 , diagnosed with TMD of Muscular / Articular origin who sought the Orofacial Pain Service (SERDOF) of the Dental School of the Federal University of Mato Grosso do Sul were selected, based on the criteria of the Research Diagnostic Criteria - RDC. The present study was approved by the Ethics Committee in human beings as protocol number CAAE 60113416.5.0000.0021.

- Application Questionnaire:

The study was carried out in two stages: the first step was the application of the Ohip-14 questionnaire, anamnestic questionnaire of Fonseca $^{6}$, and the McGill questionnaire $(\mathrm{Br}-\mathrm{MPQ})^{10}$ of orofacial pain. These questionnaires are self-explanatory and easy to understand. In the next step, after performing the appropriate clinical treatment for each cases, only the questionnaire Ohip-14 was applied to compare the results before and after the treatment of these patients (Figure 1).

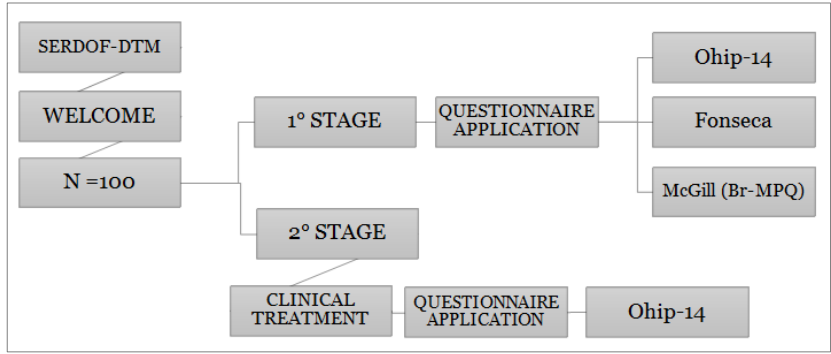

Figure 1: Structure of the application of research with patients.

The Ohip-14 questionnaire aimed to evaluate the patients' perception regarding the impact of TMD on their social activities, general well-being, and quality of life, through 14 questions established in seven domains of impact, and the numbered markers indicate the frequency in which such occurrence occurs in your daily life. These markers are numbered from 0 to 4, the number 0 indicating never, 1 almost never, 2 occasionally, 3 sometimes, 4 always, thus classifying them according to the score obtained in: low impact on quality of life (0-18 points), moderate impact (19-38 points) and high impact (39 - 56 points).

The Fonseca Anamnestic Questionnaire was used to diagnose TMD and its severity. It has the advantage of simple understanding by patients, is fast and easy to apply, and therefore, its application in the public service is ideal. The Fonseca questionnaire consists of 10 questions with three possible answers, YES (10 points), NO (0 points) and SOMETIMES (5 points), classifying the patients through the sum of points as: patients without TMD (0 to 15 points). Mild TMD (20 to 45 points), moderate TMD (50 to 65 ) and severe TMD (70 to 100 points).

Finally, the McGill pain questionnaire (Br$M P Q$ ) was used to evaluate the impact of pain in patients' lives through questions related to the social impairment, development of daily activities and perception of the patient about third-party's reactions to their painful condition in the sub-items of the categories: (1) social harm, (2) activities of daily living, (3) perception of the other, (4) tolerance, (5) sensation of being sick, (6) feeling useful, and (7) satisfaction with life. In this way, we can better understand the patient as their perception of pain and the direct relationship in which pain influences daily activities, in both physical as well as psychosocial aspects.

- Treatment Performed

In cases of muscular TMD, patients 
received treatments with: addition thermotherapy (warm compress three times a day for 15 minutes); manual therapy (rastelo massage 10 times a day); electromagnetic agents (TENS three sessions); physiotherapeutic treatment (acupuncture) and night use of stabilization plate. The treatment was carried out over a period of four months.

In cases of TMD of joint origin, patients received treatments with: subtraction thermotherapy (cold compress once a day), viscosupplementation if indicated (three sessions), anterior repositioning plate (for two months) followed by a stabilizing plate (monitoring). The treatment was carried out for four months.

\section{- Statistical Analysis}

Statistical analysis was performed before and after treatment. The OHIP-14 score was performed using Wilcoxon's non-parametric test, since the data samples did not pass the Shapiro-Wilk normality test. The evaluation of the association between the classification of the OHIP-14 score and the moment of analysis (before and after treatment) was performed using the McNemar test. The linear correlation between the score on the OHIP-14 scale and the one according to Fonseca, at the time before treatment, was performed by Spearman's linear decorrelation test. Finally, the evaluation of the association between the classification of the OHIP-14 score and the classification of the score according to Fonseca, at the time before treatment, was performed using the chi-square test, with Bonferroni correction when necessary. The other results of this study were presented in the form of descriptive statistics or in the form of charts and graphs. Statistical analysis was performed using the statistical program SPSS, version 24.0 or the SigmaPlot program, version 12.5 , considering a level of significance of $5 \%{ }^{12}$.

RESULTS

In this study, 100 patients were evaluated, and before the treatment OHIP-14 was $30.02 \pm 1.26$ (mean \pm standard error of the mean) points, after which treatment it was $8.94 \pm$ 0.63 points. The OHIP-14 score after treatment was significantly lower than that observed prior to treatment (Wilcoxon test, $p<0.001$ ). These results are presented in Figures 2 and 3 .

Table 1 shows the percentage of patients according to the OHIP-14 score classification, before and after treatment, with a significant association between these variables (McNemar test, $p<0.001)$. In this table it is possible to observe that patients with scores classified as low before treatment $(100.0 \%-n=22)$ also remained as "low" after treatment. In addition, of the 52 patients with a mean score before treatment, $88.5 \%(n=46)$ went from medium to low score. Finally, of the 26 patients with a high score before treatment, $15.4 \%(n=4)$ went from high to medium score and $84.6 \%(n=22)$ went from high to low score.

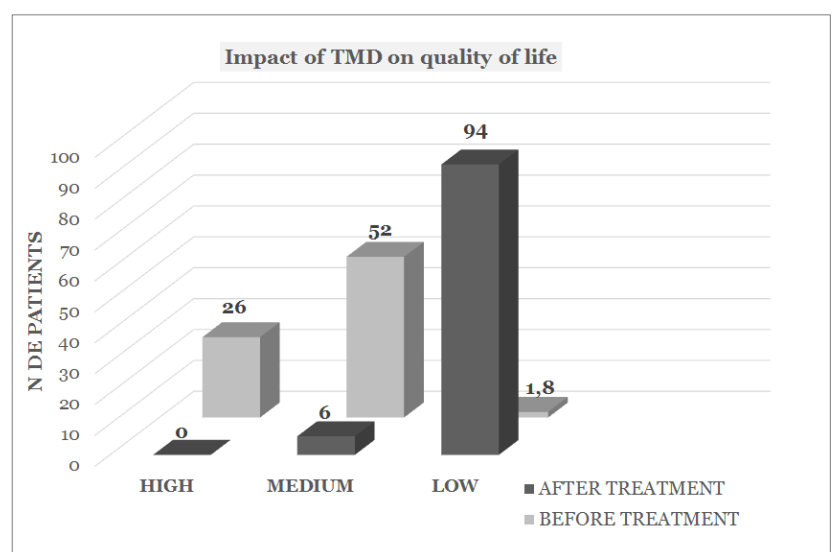

Figure 2: Percentage of patients according to OHIP-14 score classification, before and after treatment.

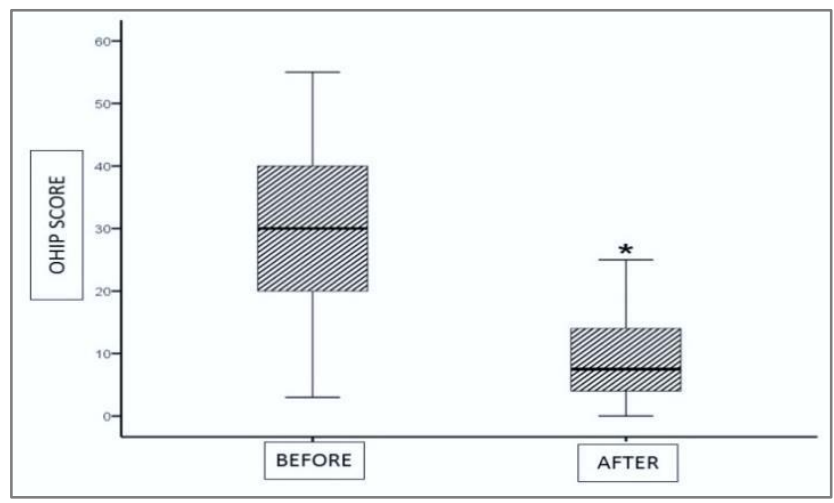

Figure 3: Box plot graph showing the median value (bold horizontal line), interquartile range 25 and $75 \%$ (box), and minimum to maximum range (vertical bar) of the OHIP-14 score before and after treatment. * Significant difference from the time before treatment (Wilcoxon test, $p<0.001$ ).

Table 1: Percentage of patients according to the OHIP-14 score, before and after treatment

Classification of the score OHIP-14 according to the moment of analyses

\begin{tabular}{c|c|c|c}
\hline \multirow{2}{*}{ After } & \multicolumn{3}{|c}{ Before } \\
\cline { 2 - 4 } & Low & Medium & High \\
\hline Low & $100.00(22)$ & $88.5(46)$ & $84.6(22)$ \\
\hline Medium & $0.0(0)$ & $11.5(6)$ & $15.4(4)$ \\
\hline High & $0.0(0)$ & $0.0(0)$ & $0.0(0)$ \\
\hline
\end{tabular}

The results are presented in relative frequency (absolute frequency).

The Fonseca scale score before treatment was $73.25 \pm 1.93$ points, classifying the group as having severe TMD.

The percentage of patients according to the OHIP-14 score classification before treatment and the Fonseca score classification is shown in Table 2. There was a significant association between OHIP-14 score classification before the treatment. Fonseca score at the same time (chi-square test, $\mathrm{p}=$ 0.035), and the percentage of patients with a high OHIP-14 score who had severe TMD according to Fonseca $(84.6 \%-\mathrm{n}=22)$ was higher than that of patients with low OHIP-14 
score and who also had severe TMD according to Fonseca $(50.0 \%-\mathrm{n}=11)$.

Table 3 shows the percentage of patients according to the answer in each domain / question of the McGill questionnaire. Regarding the domain "Social injury: pain affects", most patients reported that they did not present this type of injury in relation to loss of working days $(78.0 \%-n=78)$, sick leave $(90,0 \%-n=90)$, job loss $(93 \%-n=93)$, retirement $(99.0 \%-n=99)$ and school activities $(71.0 \%-n=71)$. On the other hand, in relation to work, leisure, home activities, family relationships and relationships with friends, most patients reported losses, ranging from less to a higher degree $(53.0 \%$ and $71.0 \%)$.

Table 2. Percentage of patients according to the classification of the OHIP-14 score before treatment and the classification of the score in the Fonseca scale

\begin{tabular}{c|c|c|c}
\hline $\begin{array}{c}\text { Fonseca } \\
\text { (before) }\end{array}$ & \multicolumn{3}{|c}{ OHIP-14 (before) } \\
\hline & Low & Medium & High \\
\hline Mild TMD & $27.3(6) \mathrm{a}$ & $7.7(4) \mathrm{a}$ & $3.8(1) \mathrm{a}$ \\
\hline Moderate TMD & $22.7(5) \mathrm{a}$ & $23.1(12) \mathrm{a}$ & $11.5(3) \mathrm{a}$ \\
\hline Severe TMD & $50.0(11) \mathrm{b}$ & $69.2(36) \mathrm{ab}$ & $84.6(22) \mathrm{a}$ \\
\hline
\end{tabular}

Table 3. Percentage of patients according to the questionnaire response in the McGill questionnaire

\begin{tabular}{|c|c|c|c|c|c|}
\hline \multirow[t]{2}{*}{ Domain/Question } & \multicolumn{5}{|c|}{ Answer } \\
\hline & No & A little & More or Less & A lot & Always \\
\hline \multicolumn{6}{|c|}{ Social Harm: the pain affects } \\
\hline & & $18.0(18)$ & $18.0(18)$ & $10.0(10)$ & \\
\hline Loss of work days & $78.0(78)$ & $9.0(9)$ & $7.0(7)$ & $6.0(6)$ & $0.0(0)$ \\
\hline Medical leave & $90.0(90)$ & $3.0(3)$ & 4.0 (4) & $2.0(2)$ & $1.0(1)$ \\
\hline Job loss & $93.0(93)$ & $2.0(2)$ & $0.0(0)$ & $4.0(4)$ & $1.0(1)$ \\
\hline $\begin{array}{l}\text { Ketrrement } \\
\text { At school }\end{array}$ & $\frac{99.0(99)}{71.0(71)}$ & $\begin{array}{l}1.0(1) \\
9.0(9)\end{array}$ & $\frac{0.0(0)}{10.0(10)}$ & $\begin{array}{l}0.0(0) \\
6.0(6)\end{array}$ & $\begin{array}{l}0.0(0) \\
4.0(4)\end{array}$ \\
\hline During leisure & $29.0(29)$ & $22.0(22)$ & $22.0(22)$ & $18.0(18)$ & \\
\hline At home & $29.0(29)$ & $22.0(22)$ & $24.0(24)$ & $19.0(19)$ & $6.0(6)$ \\
\hline \multirow{2}{*}{\multicolumn{6}{|c|}{ In the relationship with family members }} \\
\hline \multirow{2}{*}{\multicolumn{6}{|c|}{\begin{tabular}{|l|l} 
& $44.0(44)$ \\
In the relationship with friends & $18.0(18)$ \\
\end{tabular}}} \\
\hline & & & & & \\
\hline & $47.0(47)$ & $22.0(22)$ & $15.0(15)$ & $11.0(11)$ & $5.0(5)$ \\
\hline \multicolumn{6}{|l|}{ Daily Activities } \\
\hline Sleep & $29.0(29)$ & $13.0(13)$ & $24.0(24)$ & $22.0(22)$ & $12.0(12)$ \\
\hline $\begin{array}{l}\text { Initial Insomnia } \\
\text { Teminal Issomianis }\end{array}$ & $41.0(41)$ & $14.0(14)$ & $26.0(26)$ & $13.0(13)$ & $6.0(6)$ \\
\hline $\begin{array}{l}\text { Terminal nssommia } \\
\text { Not restful sleep }\end{array}$ & $\frac{61.061)}{470(47)}$ & & $\frac{16.0(16)}{16.0(16)}$ & $\begin{array}{l}14.0(14) \\
18.0(18)\end{array}$ & $\frac{2.0(2)}{10.0(10)}$ \\
\hline Appetite/Eating & $350 .(35)$ & $22.0(22)$ & $19.0(19)$ & $16.0(16)$ & $8.0(8)$ \\
\hline Personal Hygiene & $66.0(66)$ & $17.0(17)$ & $10.0(10)$ & $5.0(5)$ & $2.0(2)$ \\
\hline Getting dressed & & $9.0(9)$ & & $1.0(1)$ & $3.0(3)$ \\
\hline Locomotion & $75.0(75)$ & 11.0 (11) & $7.0(7)$ & $5.0(5)$ & $2.0(2)$ \\
\hline \multirow{2}{*}{\multicolumn{6}{|c|}{ Perception of others: the people }} \\
\hline & & & $9.0(9)$ & $3.0(3)$ & \\
\hline Express frustration & $70.0(70)$ & $16.0(16)$ & $6.0(6)$ & $7.0(7)$ & $1.0(1)$ \\
\hline $\begin{array}{l}\text { Feel anger } \\
\text { Ignore me }\end{array}$ & $\begin{array}{ll}86.0(86) \\
82.0(82)\end{array}$ & $\frac{6.0(6)}{100(10)}$ & $\begin{array}{l}3.0(3) \\
4.0(4)\end{array}$ & 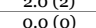 & $\begin{array}{l}3.0(3) \\
4.0(4)\end{array}$ \\
\hline & & & & & \\
\hline
\end{tabular}

Regarding the domain "Activities of daily living", most patients reported no changes in terminal insomnia $(61.0 \%-\mathrm{n}=61)$, personal hygiene $(66.0 \%-n=66)$, when wearing $(83.0 \%$ $-\mathrm{n}=83)$ and in locomotion $(75.0 \%-\mathrm{n}=75)$. On the other hand, in relation to sleep, initial insomnia, non-restorative sleep and appetite / diet, most patients reported alterations, ranging from minor to greater degree $(53.0 \%$ and $71.0 \%)$.

Regarding the domain "Perception of others: other people", most patients reported that others were not angry with them $(68.0 \%-n$ $=68)$, did not express frustration $(70.0 \%-\mathrm{n}=$ $70)$ did not feel angry at them $(86.0 \%-n=86)$ and did not ignore them $(82.0 \%-n=82)$.

Finally, the percentage of patients according to the answer to each McGill questionnaire question related to the "Personal Identification" domain is shown in Table 4. For $31 \%$ of patients $(n=31)$, tolerating pain is difficult, $40.0 \%$ of them $(n=40)$ reported feeling a little sick, $67.0 \%(n=67)$ felt useful and $82.0 \%$ of them $(n=82)$ were partially dissatisfied with life.

Table 4: Percentage of patients according to the answer in each question of the McGill questionnaire, related to the domain "Personal identification"

\begin{tabular}{l|c}
\hline \multicolumn{2}{c}{ Personal Identification regarding } \\
\hline Tolerating pain & $21.0(21)$ \\
\hline It is not difficult & $25.0(25)$ \\
\hline It is a little difficult & $31.0(31)$ \\
\hline It is difficult & $19.0(19)$ \\
\hline It is very difficult & $4.0(4)$ \\
\hline It is impossible & $47.0(47)$ \\
\hline Feeling sick & $40.0(40)$ \\
\hline No & $10.0(10)$ \\
\hline A little & $3.0(3)$ \\
\hline A lot & \\
\hline Completely & $67.0(67)$ \\
\hline Feeling useful & $28.0(28)$ \\
\hline Yes & $3.0(3)$ \\
\hline More or Less & $2.0(2)$ \\
\hline Useless & $14.0(14)$ \\
\hline Completely useless & $82.0(82)$ \\
\hline Dissatisfaction with Life & $4.0(4)$ \\
\hline Yes & $0.0(0)$ \\
\hline Partially &
\end{tabular}

\section{DISCUSSION}

Quality of life is affected by TMD more than other systemic conditions such as diabetes and hypertension, as individuals in these conditions experience major changes in their daily lives, including: loss of working day, absence of family relationship and with friends, dissatisfaction with oral health and dietary modification. In addition, pain causes suffering and limitation in daily life, causing a drama to society, due to the high cost of treatment and the cost of lost working hours ${ }^{7,11,12}$.

The participants in the present study showed a significant degree of improvement in their quality of life after TMD treatment, and before treatment the average Ohip-14 score was $30.02 \%$ and after treatment was $8.94 \%$, showing that the reduction of TMD signs and symptoms provides an improvement in quality of life. SERDOF-DTM is the only public service provided in the entire state of Mato Grosso do Sul, receiving patients from all over the state.

Regarding the Ohip-14 questionnaire and the Fonseca anamnesic questionnaire, there was a positive correlation between the severity of TMD and the high quality of life scores of patients, confirming other studies in which individuals with mild, moderate and severe TMD showed scores of the patient. Ohip-14 statistically higher than patients without TMD, which demonstrates that the severity of TMD compromises patients' quality of life $e^{5,13}$.

The data obtained in this study through 
the McGill questionnaire (Br-MPQ) showed that most patients reported no impairment in relation to lost working days $(78.0 \%)$, sick leave $(90.0 \%)$, job loss $(93 \%)$, retirement $(99.0 \%)$ and school activities $(71.0 \%)$. Having results similar to those of Oliveira et al. ${ }^{14}$, where none of the patients indicated leave or absence / absence at work due to their pain. However, in the subitem school activities in this work, there are divergences from the study cited, because more than half of the patients reported some impairment ${ }^{15}$.

Still, in relation to leisure, work, home activities, family / friends relationship, sleep and appetite / food, most patients reported damage or significant influence, varying from less to a greater degree, similarities obtained in the study data. Oliveira et al. ${ }^{14}$, where more than half of the patients also presented impairment ${ }^{15}$.

Regarding the perception of the patient to others, most of them did not feel that people became angry, expressed frustration, felt anger or ignored them, and it was possible to relate that the disorder itself exclusively affects the patient with TMD and does not change the interpersonal conviviality, since it is not perceived by peers or people around them.

This statement is justified by the percentage obtained in the present study which, according to the answer to each question in the McGill questionnaire related to the "Personal Identification" domain, presents $31 \%$ of patients claiming that tolerating pain is difficult, $40.0 \%$ reported who felt a little ill, $67.0 \%$ felt useful and $82.0 \%$ of them were partially dissatisfied with life, so the analysis made through this item reflects the individual perception, confirming and validating the coherence in these data.

Most patients reported some degree of difficulty tolerating pain and more than half said they did not feel sick. Of the total sample, 33\% of participants reported feeling less helpful due to TMD and $82 \%$ stated that their lives are not completely satisfactory, similar data obtained from the studies by Lacerda et al. $^{12}$. This percentage caused concern on the part of the researchers involved, since one third of the patients could develop or enter a more serious condition from the psychological point of view because they classify their lives as partially satisfactory ${ }^{12}$.

\section{CONCLUSION}

The patients demonstrated that the more severe the TMD clinical picture, the greater its negative impact on quality of life. The treatment carried out by the only public service in the region was effective in improving this condition.

\section{REFERENCES}

1. Locker D, Grushka M. The impact of dental and facial pain. J Dent Res. 1987;66(9):1414-17.

2. Biazevic $\mathrm{MGH}$, Araújo ME, Michel-Crosato E. Indicadores de qualidade de vida relacionados com a saúde bucal: revisão sistemática. Rev Odontol. 2002;4(1):13-25.

3. Parker MW. A dynamic model of etiology in temporomandibular disorders. J Am Dent Assoc. 1990;120(3):283-90.

4. Bocchi EA, Kuhn AMB, Nascimento RSGF. Características psicológicas de pacientes com queixa de disfunção da articulação temporomandibular. Psikhe. 2000;5(1):70-6.

5. Donnarumma MD, Muzilli CA, Ferreira C, Nemr K. Disfunções temporomandibulares: sinais, sintomas e abordagem multidisciplinar. Rev CEFAC. 2010;12(5):788-94.

6. Fonseca DMD, Bonfante G, Valle ALD, Freitas SFTD. Diagnóstico pela anamnese da disfunção craniomandibular. RGO. 1994;42(1):23-4.

7. Barros Vde M, Seraidarian PI, Côrtes MI, de Paula LV. The impact of orofacial pain on the quality of life of patients with temporomandibular disorder. J Orofac Pain. 2009;23(1):28-37.

8. John MT, Reissmann DR, Schierz O, Wassell RW. Oral health-related quality of life in patients with temporomandibular disorders. J Orofac Pain. 2007;21(1):46-54.

9. Biasotto-Gonzalez DA, Mendes PC, Jesus LA, Martins MD. Qualidade de vida em portadores de disfunção temporomandibular: um estudo transversal. Rev Inst Ciênc Saúde. 2009;27(2):128-32.

10. Pimenta CAM, Teixeira MJ - McGill Pain Questionnaire: adaptation into the portuguese language Rev Bras Anestesiol. 1997; 47(2):17786.

11. Rowe P. Essential statistics for the pharmaceutical sciences. Chichester, England: John Wiley \& Sons; 2007.

12. Lacerda JT, Traebert J, Zambenedetti ML. Dor orofacial e absenteísmo em trabalhadores da indústria metalúrgica e mecânica. Saude soc. 2008;17(4):182-91.

13. Kuroiwa DN, Marinelli JG, Rampani MS, Oliveira W, Nicodemo D. Desordens temporomandibulares e dor orofacial: estudo da qualidade de vida medida pelo Medical Outcomes Study 36 - Item Short Form Health Survey. Rev dor. 2011;12(2):93-8.

14. Oliveira AS, Bermudez CC, Souza RA, Souza CMF, Dias EM, Castro CES et al . Impacto da dor na vida de portadores de disfunção temporomandibular. J Appl Oral Scci. 2003;11(2):138-43.

15. Lemos GA, Paulino MR, Forte FDS, Beltrão RTS, Batista AUD. Influência da presença e gravidade da disfunção temporomandibular na qualidade de vida relacionada com a saúde oral. Rev dor. 2015;16(1):10-4. 


\section{CONFLICTS OF INTERESTS}

The authors declare no conflicts of interests.

\section{CORRESPONDING AUTHOR}

\section{Victor Augusto Alves Bento}

Departamento de Materiais Odontológicos e Prótese

Faculdade de Odontologia de Araçatuba, UNESP

Rua José Bonifácio, 1193

16015-050 Araçatuba - SP, Brasil

E-mail: vtrbento97@gmail.com

Received 06/10/2020

Accepted 26/01/2021 